\title{
EFEITO DA FREQÜÊNCIA DE CAPINAS NA PRODUÇÃO dO CAFEEIRO $\left({ }^{1}\right.$ )
}

\author{
SÉRGIO VASCO DE TOLEDO $\left({ }^{2}\right)$, MÁRIO VIEIRA DE MORAES $\left({ }^{2,3}\right)$ e INÁCIO DE BARROS ${ }^{2}$ )
}

\begin{abstract}
RESUMO
Foram estudados quatro intervalos entre capinas manuais com enxada em cafezais e uso de herbicidas, e seu efeito sobre a produção, de 1959 a 1973. Os tratamentos foram: intervalos entre capinas de $15,30,45$ e 60 dias, e aplicação de herbicidas (três vezes ao ano). Os resultados mostraram não haver diferenças entre a capina manual e a química na produção do cafeeiro; o intervalo de 45 dias entre capinas foi o que mais favoreceu a produção do cafeeiro, além de ser o mais econômico. $\mathrm{O}$ grande desenvolvimento do mato entre o $45 .^{\circ}$ e o $60 .^{\circ}$ dia de intervalo entre capinas aumentou bastante o custo da capina posterior. Houve grande absorção de $\mathrm{PO}_{4}$ pelas plantas invasoras na fase final de desenvolvimento, uma vez que, aos 60 dias, o mato encontra-se florescido e/ou frutificado.
\end{abstract}

Termos de indexação: café, tratos culturais, controle do mato.

\section{ABSTRACT \\ EFFECTS OF WEEDING FREQUENCY ON COFFEE YIELD}

The effects of four intervals of manual/hoeing compared to chemical/herbicides weeding were studied in coffee yield plantations for the $1959-1973$ period. The treatments were: a) weeding intervals of $15,30,45$ and 60 days; b) application of herbicides (three times per year). The results showed that there were no differences between manual and chemical weeding in coffee beans production. The procedure of the $45^{\text {th }}$ day interval between weedings showed better effect on coffee yield and was the least expensive. The intense weed development between the $45^{\text {th }}$ and $60^{\text {th }}$ day interval between weedings increased the costs of the successive weeding. Higher $P$ absorption by weed plants was found when the weeds reached the flowering and/or maturing stage of growth.

Index terms: coffee, crop management, weeding.

( $\left.{ }^{1}\right)$ Recebido para publicação em 25 de julho de 1995 e aceito em 4 de abril de 1996.

(2) Seção de Café, Instituto Agronômico (IAC), Caixa Postal 28, 13001-970 Campinas (SP).

(3) Seção de Café, IAC. Aposentado. 


\section{INTRODUÇÃO}

As plantas invasoras competem com as cultivadas por água, luz e nutrientes. Segundo Robinson (1956), análises foliares de cafeeiros mantidos em áreas desprovidas de invasoras apresentavam $2,12 \%$ de nitrogênio, enquanto, em áreas constantemente infestadas, esse teor caiu para $1,87 \%$, ocorrendo o mesmo com o teor de $\mathrm{N}$ nítrico nos primeiros $30 \mathrm{~cm}$ de solo.

Os teores de nutrientes podem ser bastante elevados em algumas espécies vegetais. Gallo et al. (1958) verificaram teores altos de potássio e magnésio em beldroegas (Portulaca oleracea L.) e nitrogênio em amendoim-bravo (Euphorbia prunifolia Jacq.), sendo os nutrientes mais extraídos pelas espécies estudadas o nitrogênio e o potássio. Resultados semelhantes foram obtidos por Miguel et al. (1980), afirmando ser as plantas invasoras capazes de extrair $97 \mathrm{~kg}$ de $\mathrm{N}, 7 \mathrm{~kg}$ de $\mathrm{P}_{2} \mathrm{O}_{5}, 60 \mathrm{~kg}$ de $\mathrm{K}_{2} \mathrm{O}, 42 \mathrm{~kg}$ de $\mathrm{CaO}$ e $9 \mathrm{~kg}$ de $\mathrm{MgO}$ por hectare, resultados bastante diferentes dos encontrados por Pereira \& Jones (1954) para o fosfato, os quais determinaram extrações de 17,5 a $21 \mathrm{~kg}$ de $\mathrm{P}_{2} \mathrm{O}_{5}$, quantidades essas superiores às extraídas por uma colheita equivalente a $4.000 \mathrm{~kg}$ de café em coco. Esses nutrientes retornam ao solo com as capinas; entretanto, sua maior atividade extrativa ocorre principalmente no período chuvoso, conforme Oliveira et al. (1979. 1985), e Blanco et al. (1979), justamente na época de formação e maturação dos frutos de café, concorrendo, portanto, com estes.

Essa concorrência, evidentemente, afeta diretamente a produção. Marques et al. (1957), em solos de terra roxa e arenito Bauru, verificaram produções de 1.065 e $1.043 \mathrm{~kg}$ de café beneficiado/mil covas com o uso de capinas frequentes, enquanto, com capinas apenas com o mato selecionado, as produções foram de 534 e $695 \mathrm{~kg} / \mathrm{mil}$ covas.

Quedas de produção também foram observadas por Pereira \& Jones (1954), os quais identificaram $47 \%$ de diferença na produção entre cafeeiros mantidos no limpo e os permanecidos no mato durante o período chuvoso. Entretanto, Lorenzi \& Almeida (1978) afirmam que capinas sucessivas são prejudiciais ao cafezal. Blanco et al. (1979) e Oliveira et al. (1985) concluíram que o cafezal deve ser mantido limpo durante todo o período chuvoso.

Quanto ao sistema de controle das invasoras, Silveira et al. (1977) mostraram que o controle das plantas invasoras, através do uso de grade, conferiu maior produção, enquanto Jabor et al. (1985) concluíram que a capina química é superior à manual. Com relação à produção do café no biênio $84 / 85$ entretanto, Jabor et al. (1987) observaram não haver diferença entre a produção das parcelas com capina manual e química no quadriênio 1984/87. Para áreas montanhosas, Matiello et al. (1989) afirmam que a capina química é melhor que a manual ou a roçada, talvez pela proteção do solo proporcionada pelo mato seco.

No tocante às recomendações do número de capinas para cafezais, Fernandes (1986) determina que sejam feitas quatro por ano e Scaranari (1955), cinco, no período das chuvas.

O presente trabalho teve por objetivo conhecer o número de capinas a que deve ser submetido o cafeeiro, a fim de minimizar o efeito da concorrência das plantas invasoras sobre sua produção.

\section{MATERIAL E MÉTODOS}

O ensaio foi instalado no Centro Experimental de Campinas do Instituto Agronômico, em cafezal da variedade Bourbon Amarelo plantado em 1953. O estado vegetativo das plantas, quando da instalação do ensaio, em 1959, era bom e vinha apresentando produções médias ao redor de $1.350 \mathrm{~kg} / \mathrm{ha}$ de café beneficiado. As adubações fornecidas a esses cafeeiros, desde 1955, foram exclusivamente químicas, em quantidades capazes de restituir às plantas os nutrientes extraídos pelas colheitas, segundo bases científicas. O espaçamento era de $4,0 \times 2,0 \mathrm{~m}$, em solo do tipo latossolo roxo.

No delineamento experimental - blocos ao acaso com sete repetições - cada parcela era constituída de dez covas: oito úteis e duas de bordadura. As covas eram formadas por três plantas e, dentro da parcela, estavam dispostas na mesma linha, havendo uma linha de bordadura a cada lado da linha útil, sendo colhidas, anualmente, as produções apresentadas, e calculadas as estimativas de produção em 
quilograma/hectare. Com o objetivo de complementar as observações, nos anos agrícolas de $62 / 63 \mathrm{e}$ 63/64, realizaram-se cronometragens do tempo médio gasto para efetuar a capina nas parcelas e calculou-se a estimativa do tempo gasto por hectare. Também foram realizadas, em junho de 1966, análises químicas do solo, com o objetivo de verificar possíveis alterações em função dos tratamentos.

Os tratamentos, efetuados durante o período chuvoso, que correspondia ao intervalo entre setembro e abril, eram os seguintes: (1) capina de 15 em 15 dias; (2) capina de 30 em 30 dias; (3) capina de 45 em 45 dias; (4) capina de 60 em 60 dias; (5) uso de herbicida (três aplicações).

O herbicida utilizado foi, até 1964 , uma mistura de 2,4-D + TCA nas duas primeiras aplicações, enquanto, na última, adicionaram-se Diuron ou Simazim. Esse tratamento exigia, todos os anos, uma capina em maio, a fim de efetuar a colheita no limpo. A partir do ano agrícola 64/65, o controle passou a ser feito com paraquate conjugado com 2,4-D e espalhante adesivo, não necessitando mais a capina em maio.

As produções dos anos 64 e 70 foram desconsideradas, uma vez que, devido a fatores climáticos (63-seca; 69-geada), foram extremamente reduzidas (menores que $5 \mathrm{~kg} / \mathrm{ha}$ ).

O levantamento botânico das espécies vegetais invasoras existentes, realizado em 23/12/58, apresentou a composição constante do quadro 1 .

\section{RESULTADOS E DISCUSSÃO}

O quadro 2 apresenta a análise da variância em 1959-1973: como era de esperar, o efeito de ano foi altamente significativo. Isso é inerente ao próprio comportamento do cafeeiro, por apresentar ciclo bienal de produção (Figura 1).

O efeito de tratamentos tambćm foi altamente significativo e o teste de Tukey para estes - Quadro 3 - mostra ser a capina a cada 15 dias, durante o período chuvoso, o pior tratamento.

Para o período 1959-73, as produções médias de cada tratamento podem ser observadas no quadro 4 .

Foram feitas análises da variância para a colheita em branco de 1959, para os quadriênios 1960-63 e 1965-68, para 1969, para o triênio de 71-73 e da média geral 60-73. Um resumo dessa análise é apresentado no quadro 5 , bem como as médias de produção dos períodos estudados. Verifica-se que não houve diferenças significativas entre a capina manual e a química. Contudo, entre as capinas manuais, os intervalos revelaram-se significativos ao modelo quadrático. Mediante análise de regressão, verificou-se que os melhores intervalos entre capinas encontrados foram: 43 dias para o quadriênio 60-63; 40 dias para 1969 e 39 dias para o quadriênio 60-63 e também na média de todos os anos estudados (período 19601973).

Quadro 1. Levantamento botânico das espécies vegetais invasoras em 23 de dezembro de 1958

\begin{tabular}{lllc}
\hline Nome comum & \multicolumn{1}{c}{ Nome botânico } & Família & Grau infestação \\
\hline & & & $\%$ \\
Beldroega & Portulaca oleracea L. & Portulacaceae & 65 \\
Capim-colchão & Digitaria sanguinalis Scop. & Gramineae & 15 \\
Caruru & Amaranthus viridis L. & Amaranthaceae & 10 \\
Carrapicho & Cenchrus echinatus L. & Gramineae & 5 \\
Marmelada & Brachiaria plantaginea (Link) Hitch. & Gramineae & 4 \\
Erva-tostão & Boerhavia hirsuta Willd L. & Nyctaginaceae & 1 \\
Malva & Malva parviflora L. & Malvaceae & 1 \\
Picão-preto & Bidens pilosa L. & Compositae & 1 \\
Guanxuma & Sida cordifolia L. & Malvaceae & 1 \\
Mentrasto & Ageratum conyzoides L. & Compositae & 1 \\
\hline
\end{tabular}


Quadro 2. Resultado da análise da variância dos dados de produção obtidos em quilograma de café beneficiado/hectare em experimento de capinas no cafeeiro, realizado em Campinas, no período 1959-1973

\begin{tabular}{lcc}
\hline Fonte de variação & G.L. & Quadrado médio \\
\hline Bloco & 6 & $4184297^{* *}$ \\
Ano & 12 & $25205081^{* *}$ \\
Tratamento & 4 & $1198209^{*}$ \\
Ano x tratamento & 48 & $214691 \mathrm{~ns}$ \\
Resíduo & 384 & 337170 \\
C.V.(\%) & 33,595 & - \\
\hline
\end{tabular}

Quadro 3. Médias de tratamentos para os resultados de produção obtidos em quilograma de café beneficiado/hectare em experimento de capinas no cafeeiro, realizado em Campinas, em 1959-1973

\begin{tabular}{lc}
\hline Tratamento & Média $\left({ }^{1}\right)$ \\
\hline Capina de $45-45$ dias & $1867 \mathrm{a}$ \\
Capina de $30-30$ dias & $1837 \mathrm{ab}$ \\
Capina de $60-60$ dias & $1665 \mathrm{ab}$ \\
Herbicida & $1656 \mathrm{ab}$ \\
Capina de $15-15$ dias & $1618 \mathrm{~b}$ \\
DMS & 228,97 \\
\hline
\end{tabular}

(1) Médias seguidas de mesma letra não diferem, entre si, pelo teste de Tukey a $5 \%$.
Até o período de 45 dias de intervalo, as produções aumentaram conforme se pode ver na figura 2 , decrescendo após esse intervalo.

A superfície do terreno, quando carpido a intervalos de 15 dias, mantém-se descoberta, aumentando - transporte de partículas do solo pelas chuvas e a variação na temperatura do solo em função da temperatura ambiental, o que pode diminuir a ação da flora microbiana do solo.

Por outro lado, com capinas a cada 60 dias, a maioria das plantas invasoras já havia florescido e/ou frutificado, fase em que revelam maior absorção de nutrientes. Isso parece, ao que mostram os dados, estar concorrendo com parte da absorçāo pelo cafeeiro e, possivelmente, de forma mais competitiva.

O intervalo entre capinas ao redor de 40-45 dias no período chuvoso foi o que mais favoreceu a produção do cafeeiro, além de ser o mais econômico, uma vez que se precisou de 18 homens-dia por hectare por ano nas condições do ensaio, enquanto, nos intervalos de 60 dias, necessitou-se de 42 homens-dia por hectare por ano (Quadro 6).

Esse fato se deveu a que, com 60 dias, a infestação do terreno estava alta com as plantas invasoras, as quais apresentavam seu máximo desenvolvimento, concordando com Fernandes (1986), que afirma ser o rendimento das capinas muito baixo, aumentando seu custo nesse caso.

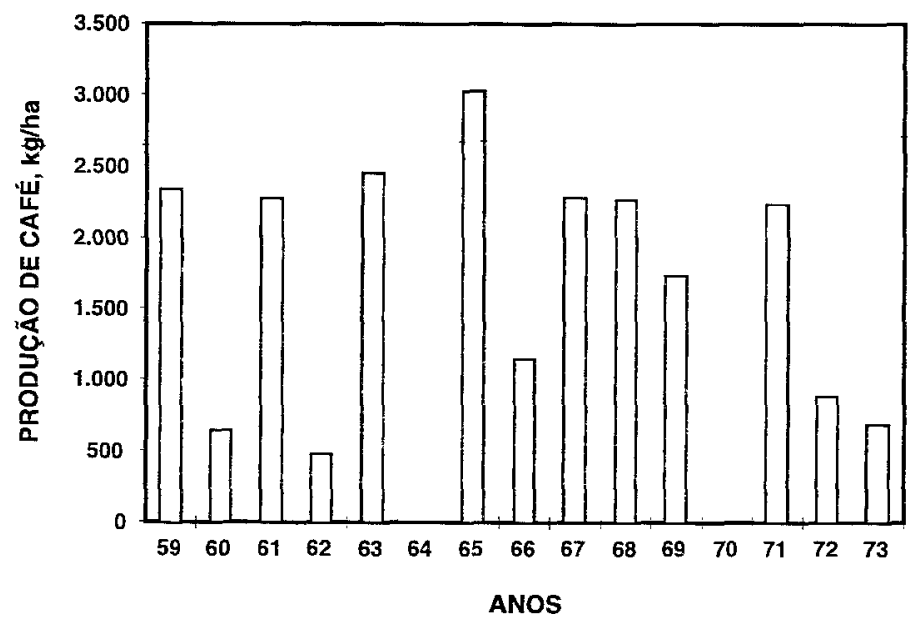

Figura 1. Produção em quilograma/hectare de café beneficiado nos anos estudados (média de sete repetições) 
Quadro 4. Médias de tratamentos para os resultados anuais de produção obtidos em quilograma de café beneficiado/hectare em experimento de capinas no cafeeiro, realizado em Campinas, no período 1959-1973 ( $\left.{ }^{1}\right)$

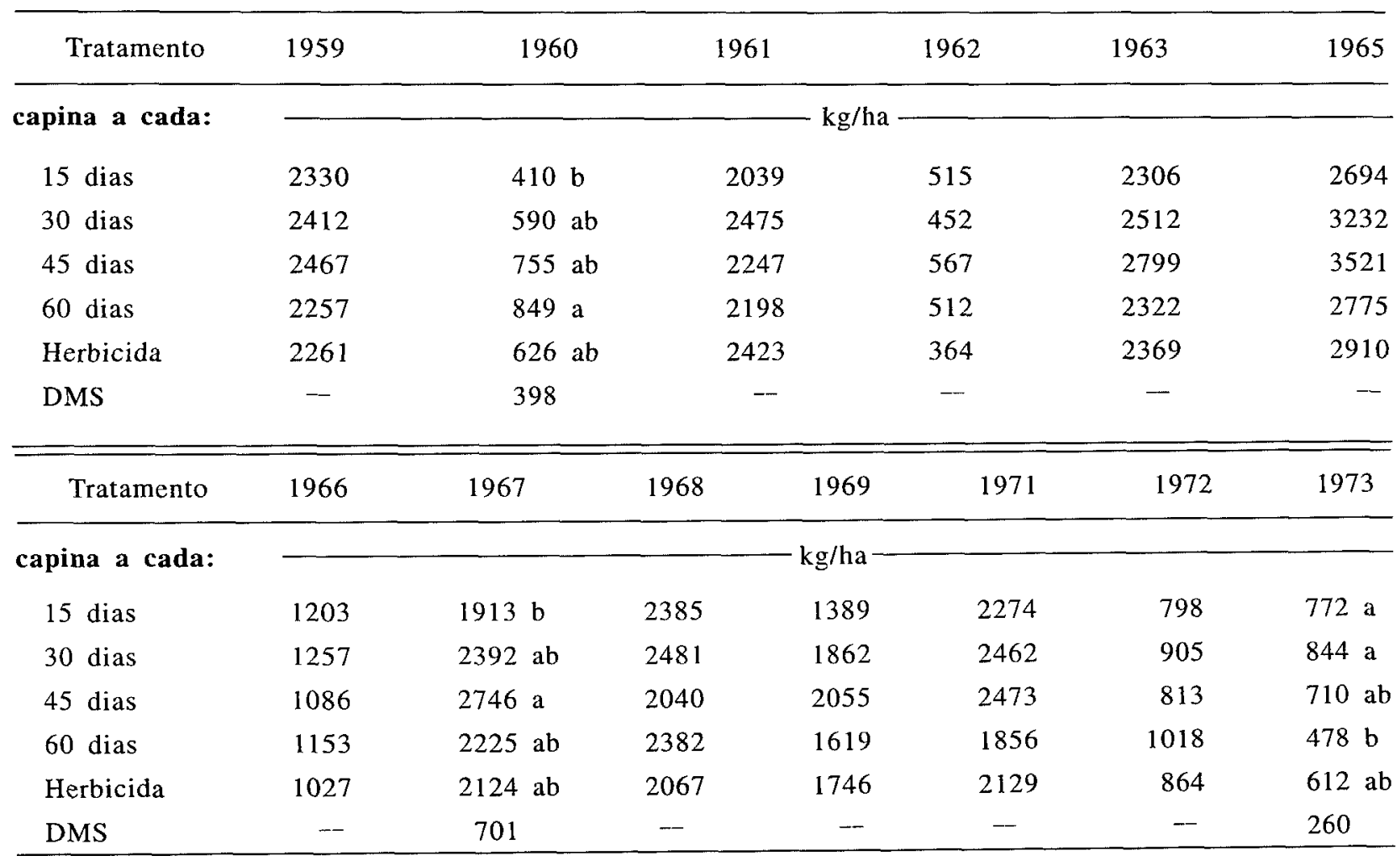

( ${ }^{1}$ ) Médias seguidas de mesma letra não diferem, entre si, pelo teste de Tukey a $5 \%$.

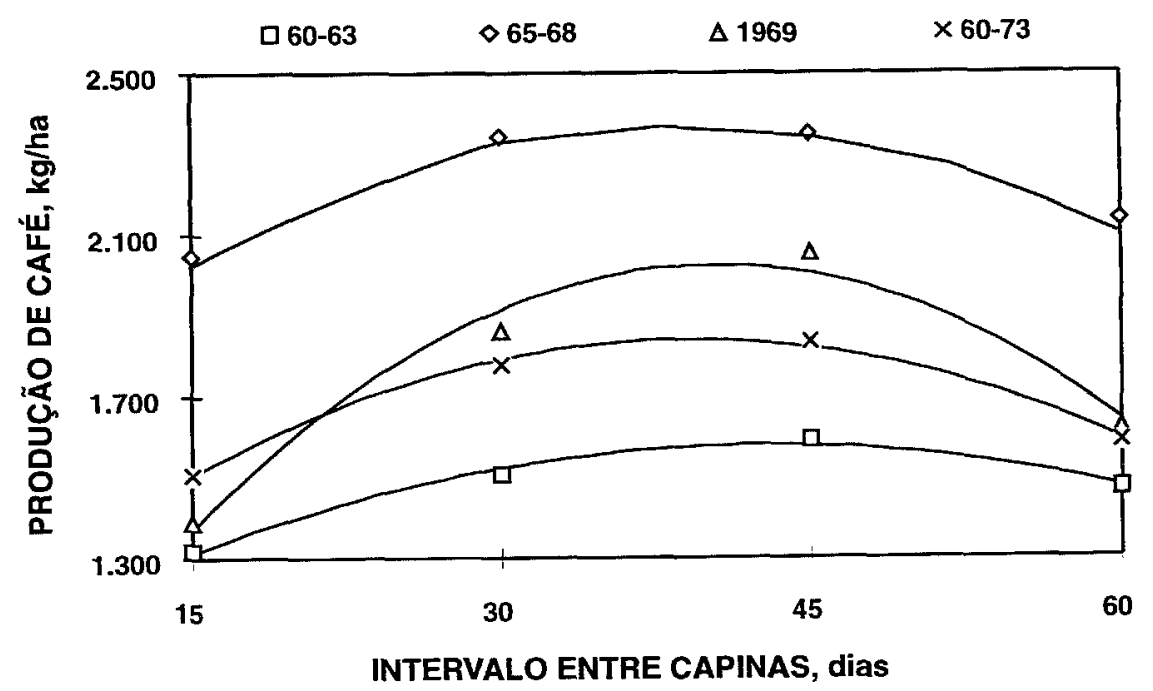

Figura 2. Curvas de resposta da produção de café beneficiado em quilograma/hectare em função do intervalo entre capinas manuais nos diferentes períodos estudados. 
A análise de solo realizada em amostras retiradas em junho de 1966 encontra-se no quadro 7 , onde se observa que houve, até a data da amostragem, pouca alteração nas características químicas do solo entre os tratamentos; apenas o teor de $\mathrm{PO}_{4}$ mostrou-se bastante reduzido nos tratamentos com herbicidas e capinas a cada 60 dias, dando a entender que as plantas invasoras absorveram maior quantidade de $\mathrm{PO}_{4}$ na fase final de seu desenvolvimento.

Quadro 5. Médias de tratamentos e resumo da análise da variância em períodos determinados, para os resultados de produção obtidos em quilograma de café beneficiado/hectare, em experimento de capinas no cafeeiro, realizado em Campinas, em 1959-1973

\begin{tabular}{|c|c|c|c|c|c|c|c|}
\hline Tratamento & 1959 & \multicolumn{2}{|c|}{$1960-63$} & $1965-68$ & 1969 & $1971-73$ & $1960-73$ \\
\hline \multicolumn{8}{|l|}{ capina a cada: } \\
\hline 15 dias & 2.330 & 1.318 & \multicolumn{2}{|c|}{2.048} & 1.389 & 1.282 & 1.509 \\
\hline 30 dias & 2.412 & 1.507 & \multicolumn{2}{|c|}{2.341} & 1.862 & 1.403 & 1.778 \\
\hline 45 dias & 2.467 & 1.592 & \multicolumn{2}{|c|}{2.348} & 2.055 & 1.332 & 1.832 \\
\hline 60 dias & 2.257 & 1.470 & \multicolumn{2}{|c|}{2.134} & 1.620 & 1.117 & 1.585 \\
\hline Herbicida & 2.261 & 1.446 & \multicolumn{2}{|c|}{2.032} & 1.746 & 1.202 & 1.606 \\
\hline Causa de variação & GL & QM & QM & QM & $\mathrm{QM}$ & QM & QM \\
\hline Blocos & 6 & $90.392 \mathrm{~ns}$ & $347.716^{* *}$ & $594.080 * *$ & $274.655^{* *}$ & $58.628 \mathrm{~ns}$ & $573.984^{* *}$ \\
\hline Tratamentos & (4) & $60.211 \mathrm{~ns}$ & $69.963 \mathrm{~ns}$ & $167.538 \mathrm{~ns}$ & $440.794 \mathrm{~ns}$ & $87.038 \mathrm{~ns}$ & $130.978 \mathrm{~ns}$ \\
\hline Enxada $x$ herbicida & 1 & $62.037 \mathrm{~ns}$ & $3.859 \mathrm{~ns}$ & $193.222 \mathrm{~ns}$ & $1.114 \mathrm{~ns}$ & $37.459 \mathrm{~ns}$ & $27.236 \mathrm{~ns}$ \\
\hline Capina a enxada & (3) & $59.602 \mathrm{~ns}$ & $92.003 \mathrm{~ns}$ & $158.978 \mathrm{~ns}$ & $587.362 \mathrm{~ns}$ & $103.567 \mathrm{~ns}$ & $165.560 *$ \\
\hline Linear & 1 & $9.542 \mathrm{~ns}$ & $102.880 \mathrm{~ns}$ & $24.685 \mathrm{~ns}$ & $274.848 \mathrm{~ns}$ & $111.898 \mathrm{~ns}$ & $27.752 \mathrm{~ns}$ \\
\hline Quadrático & 1 & $149.497 \mathrm{~ns}$ & $169.557^{*}$ & $450.848 *$ & $1.445 .101 * *$ & $197.909 \mathrm{~ns}$ & $466.454^{* *}$ \\
\hline Cúbico & 1 & $19.965 \mathrm{~ns}$ & $3.550 \mathrm{~ns}$ & $1.402 \mathrm{~ns}$ & $42.138 \mathrm{~ns}$ & $896 n s$ & $2.452 \mathrm{~ns}$ \\
\hline Resíduo & 24 & 83.259 & 33.545 & 99.637 & 191.841 & 50.610 & 54.935 \\
\hline C.V. (\%) & -- & 12.303 & 12.849 & 14.475 & 25.255 & 17.756 & 14.102 \\
\hline
\end{tabular}

Quadro 6. Tempo médio gasto para capinar um hectare, determinado nos anos agrícolas de 1962-63 e 1963-64, em experimento de capinas no cafeeiro, realizado em Campinas, em $1959-1973$

\begin{tabular}{|c|c|c|c|c|c|}
\hline \multirow{2}{*}{ Tratamento } & \multirow{2}{*}{ Capinas/ano } & \multicolumn{2}{|c|}{ Tempo médio gasto } & \multicolumn{2}{|c|}{ Homens/dia } \\
\hline & & Por capina & Por ano & Por capina & Por ano \\
\hline \multicolumn{6}{|c|}{ capina a cada: } \\
\hline 15 dias & 17 & $14 \mathrm{~h} 16 \mathrm{~min}$ & $142 \mathrm{~h} 32 \mathrm{~min}$ & 1,8 & 30 \\
\hline 30 dias & 9 & $19 \mathrm{~h} 40 \mathrm{~min}$ & $176 \mathrm{~h}$ & 2,4 & 22 \\
\hline 45 dias & 6 & $24 \mathrm{~h} 40 \mathrm{~min}$ & $148 \mathrm{~h}$ & 3,0 & 18 \\
\hline 60 dias & 4 & $85 \mathrm{~h} 28 \mathrm{~min}$ & $341 \mathrm{~h} 52 \mathrm{~min}$ & 10,6 & 42 \\
\hline
\end{tabular}


Quadro 7. Resultados da análise química do solo realizada em 1966, em experimento de capinas no cafeeiro, realizado em Campinas, em 1959-1973

\begin{tabular}{llllll}
\hline Tratamento & $\mathrm{pH}$ & $\mathrm{C}$ & $\mathrm{PO}_{4}$ & $\mathrm{~K} \mathrm{O}^{2}$ & $\mathrm{Ca}+\mathrm{Mg}$ \\
\hline capina a cada: & & & & & \\
\multicolumn{1}{l}{15 dias } & 5,23 & 16,4 & 1,4 & 1,3 & 35,3 \\
30 dias & 5.44 & 20,0 & 1,4 & 1,1 & 37,0 \\
45 dias & 5,61 & 18,9 & 1,5 & 1,5 & 41.7 \\
60 dias & 5,47 & 19,0 & 0,8 & 1,8 & 40,7 \\
Herbicida & 5,47 & 18,0 & 0,7 & 2,2 & 36,9 \\
\hline
\end{tabular}

Com intervalos de 45 dias são executadas seis capinas no período setembro/abril, número esse pouco superior ao recomendado por técnicos do IBC (1986), os quais recomendam quatro a cinco capinas anuais; entretanto, coincidente com Thomaziello et al. (1987), de 30 a 45 dias de intervalo.

\section{CONCLUSÕES}

1. Nas condições do ensaio, o uso de herbicidas não alterou, de forma estatisticamente significativa, a produção do cafeeiro em relação ao uso de capinas manuais.

2. O controle de plantas invasoras não alterou a característica de bienuidade da produção do cafeeiro.

3. O intervalo entre capinas manuais ao redor de 40-45 dias foi o que mais favoreceu a produção do cafeeiro.

4. Intervalos entre capinas de 45 dias apresentaram maior rendimento da operação, enquanto, com 60 dias, o grande desenvolvimento das plantas invasoras diminuiu o rendimento das capinas.

\section{REFERÊNCIAS BIBLIOGRÁFICAS}

BLANCO, H.G.: OLIVEIRA, D.A. \& PUPO, E.I.H. Período crítico de competição produzido por comunidade natural de mato em lavoura de café $\mathrm{cm}$ formação. In: CONGRESSO BRASILEIRO DE PESQUISAS CAFEEIRAS, 7., Araxá, 1979. Resumos. Rio de Janeiro, IBC-GERCA. 1979. p.19-21.
FERNANDES, D.R. Manejo do cafezal. In: RENA, A.B.; MALAVOLTA, E.; ROCHA, M. \& YAMADA, T. Cultura do cafeeiro: fatores que afetam a produtividade. Piracicaba, Associação Brasileira para Pesquisa da Potassa e do Fosfato, 1986. p.275-301.

GALLO, J.R.; MORAES, F.R.P. de; LOTT. W.L. \& INFORZATO, R. Absorção de nutrientes pelas ervas daninhas e sua competiçâo com o cafeeiro. Campinas, Instituto Agronômico, 1958. 27p. (Boletim. 104)

INSTITUTO BRASILEIRO DO CAFÉ (IBC). Grupo Executivo de Racionalização da Cafeicultura. Cultura do café no Brasil: pequeno manual de recomendaçōes. Rio de Janeiro, 1986. $215 \mathrm{p}$.

JABOR. J.F.; MATIELLO, J.B. \& FABRIS, E.J. Sistemas de capina em café arábica - Resultados preliminares. In: CONGRESSO BRASILEIRO DE PESQUISAS CAFEEIRAS, 12., Caxambu, 1985. Resumos. Rio de Janeiro, IBC-GERCA, 1985. p.78

JABOR. J.F.; MATIELLO, J.B. \& FABRIS, E.J. Sistemas de capina em café arábica no Estado do Espírito Santo. In: CONGRESSO BRASILEIRO DE PESQUISAS CAFEEIRAS, 14., Campinas, 1987. Resumos. Rio de Janeiro, IBC-GERCA, 1987. p.67-69.

LORENZI, H.J. \& ALMEIDA, F.S. de. Estudo da eficiência de várias técnicas de controle de ervas daninhas na cultura do café. In: CONGRESSO BRASILEIRO DE PESQUISAS CAFEEIRAS. 6., Ribeirão Preto, 1978. Resumos. Rio de Janeiro, IBC-GERCA, 1978. p.4.

MARQUES, J.Q.A.; BERTONI, J.; MENDES, J.E.T.: REIS, A.J. \& CASTRO, G.P. Efeito na produção de práticas conservacionistas de caráter vegetativo em cafezal. In: INSTITUTO AGRONÔMICO (Campinas). Relatório da Seção de Conservação do Solo, 1956-57. Campinas, 1957. p.98-99. (datilografado) 
MATIELLO, J.B.; FABRIS, E.J. \& HASHIZUME, H. Sistemas de controle do mato em cafezais em áreas montanhosas. In: CONGRESSO BRASILEIRO DE PESQUISAS CAFEEIRAS, 15., Maringá, 1989. Resumos. Rio de Janeiro, IBC-GERCA, 1989. p.219.

MIGUEL, A.E.; PEREIRA, J.E. \& OLIVEIRA, J.A. Mobilização de nutrientes pelas plantas daninhas na cultura do café. In: CONGRESSO BRASILEIRO DE PESQUISAS CAFEEIRAS, 13., Campos do Jordão, 1980. Resumos. Rio de Janeiro, IBC-GERCA, 1980. p.44-46.

OLIVEIRA, J.A.; MATIELLO, J.B. \& CARVALHO, F. Estudo do efeito da época de controle das plantas daninhas sobre a produção do café. In: CONGRESSO BRASILEIRO DE PESQUISAS CAFEEIRAS, 7., Araxá, 1979. Resumos. Rio de Janeiro, IBC-GERCA, 1979. p.350-352.

OLIVEIRA, J.A.; MATIELLO, J.B. \& CARVALHO, F. Estudo da época e número de capinas no controle de plantas daninhas na cultura do café. In: CONGRESSO BRASILEIRO DE PESQUISAS CAFEEIRAS, 12., Caxambu, 1985. Resumos. Rio de Janeiro, IBC-GERCA, 1985. p.3-7.
PEREIRA, A.C. \& JONES, P.A. A tillage study in Kenya coffee. Part I. The effects of tillage practices on coffee yields. The Empire Journal of Experimental Agriculture, Kenya, 22:23-36, 1954.

ROBINSON, I.B.A. Extracts from the annual reports of the agricultural chemist (Coffea Services), 1954 and 1955. Bulletin Coffee Board of Kenya, Ruiru, 21:158160, 1956.

SCARANARI, H.J. A cultura do café: tratos culturais do cafeeiro. São Paulo, Departamento de Produção Agrícola, 1955. 8p. (Boletim, 23)

SILVEIRA, G.M. da; KURACHI, S.A.H. \& FUJIWARA, M. Métodos mecânicos e químicos de controle de ervas daninhas em cafezal. In: CONGRESSO BRASILEIRO DE PESQUISAS CAFEEIRAS, 5., Guarapari, 1977. Resumos. Rio de Janeiro, IBC-GERCA, 1977. p.139-141.

THOMAZIELLO, R.A.; OLIVEIRA, E.G. de \& TOLEDO FILHO, J.A. de. Cultura do café. Campinas, CECOR/CATI, 1987. 122 p. (Boletim técnico, 193) 